\title{
Optimalisasi Laporan Keuangan PT. Pegadaian dengan Pendekatan Metode Lexicographic Goal Programming dan Simpleks yang Dimodifikasi
}

\author{
Sri Basriati ${ }^{*}$, Elfira Safitri ${ }^{2}$, Nurul Izzah $^{3}$ \\ 1,2,3 UIN Sultan Syarif Kasim Riau \\ *sribasriati@uin-suska.ac.id
}

\begin{abstract}
ABSTRAK
PT. Pegadaian merupakan lembaga keuangan yang melayani masyarakat untuk mendapatkan dana pinjaman. Setiap lembaga keuangan harus membuat laporan keuangan sebagai suatu bentuk pertanggungjawaban atas hasil kinerja dalam periode tertentu. Laporan keuangan PT. Pegadaian tersebut akan dianalisa menggunakan model goal programming. Metode yang digunakan dalam penyelesaian model goal programming tersebut yaitu metode lexicographic goal programming dan simpleks yang dimodifikasi untuk mendapatkan solusi optimal. Optimalisasi dengan metode lexicographic goal programming dilakukan dengan mendahulukan prioritas pertama hingga berikutnya, sedangkan metode simpleks yang dimodifikasi menganggap setiap prioritas sama pentingnya. Berdasarkan hasil penelitian bahwa kedua metode mendapatkan solusi optimal dan iterasi yang sama, yaitu sebanyak enam iterasi. Tujuan model yaitu, aset, liabilitas, ekuitas, pendapatan dan beban dapat dicapai. Berdasarkan lima tujuan tersebut, tiga tujuan seperti total ekuitas, total pendapatan dan total beban dapat diubah untuk meningkatkan kinerja laporan keuangan. Total ekuitas dapat ditingkatkan sebesar Rp. 3.186.129,- per tahun, total pendapatan dapat ditingkatkan sebesar Rp. 957.800,- dan total beban dapat diturunkan sebesar Rp. 436.141,- per tahun. Kata kunci: Goal Programming, Laporan Keuangan, Lexicographic dan Simpleks Modifikasi.
\end{abstract}

\section{ABSTRACT}

PT. Pegadaian which is a financial institution that serves the community to get loan funds. Each financial institution must make a financial report as a form of accountability for the results of performance in a certain period. Financial report of PT. The pawnshop will be analyzed using the goal programming model. The method used in the problem solving is the lexicographic goal programming method and the modified simplex to obtain the optimal solution. Optimization using the lexicographic goal programming method is carried out by prioritizing the first priority to the next, while the modified simplex method considers each priority as important. Based on the result of that research both methods obtained the optimal solution and the same iterations, namely six iterations. The objective of the model is that assets, liabilities, equity, income and expenses can be achieved. Based on these five objectives, three objectives such as total equity, total income and total expenses can be changed to improve the performance of financial statements. Total equity can be increased by Rp. 3,186,129, - every year, the total income can be increased by Rp. 957,800, - and the total expense can be reduced by Rp. 436,141, - every year.

Keywords: financial statement, goal programming, lexicographic and simplex modification. 


\section{PENDAHULUAN}

PT. Pegadaian sebagai lembaga keuangan merupakan badan usaha milik negara yang memiliki bertugas melayani masyarakat mendapatkan dana pinjaman secara cepat. Setiap lembaga keuangan akan menyusun laporan keuangan setiap tahunnya sebagai bentuk pertanggungjawaban akan hasil kinerja pada periode tertentu. Pertanggungjawaban tersebut dapat berupa arus masuk maupun arus keluar. Selanjutnya akan dianalisa untuk mencapai beberapa tujuan. Hasil analisa laporan akan memberikan informasi tentang kelemahan dan kekuatan yang dimiliki oleh lembaga keuangan tersebut. Kelemahan dan kekuatan dari hasil analisis laporan keuangan dapat dijadikan patokan dalam mengambil kebijakan oleh PT. Pegadaian dalam meningkatkan kinerja periode tahun selanjutnya sehingga diperoleh hasil laporang yang optimal.

Solusi optimal untuk laporan keuangan dapat diperoleh menggunakan pendekatan model matematika, salah satunya yaitu goal programming. Model goal programming merupakan suatu model matematis untuk pemecahan masalah dengan multi tujuan melalui variabel deviasinya. Variabel deviasi digunakan untuk menentukan penyimpangan-penyimpangan yang terjadi di atas target maupun di bawah target.

Model goal programming sudah banyak diteliti oleh ahli matematika. Babaei, H., dkk (2009) membahas pengambilan keputusan muti objektif tentang pemilihan portofolio berdasarkan prioritas dan nilai target. Orumie (2013) telah mengembangkan generalisasi algoritma goal programming yang efisien. Penelitian sebelumnya yang menggunakan metode lexicographic dan metode simpleks yang dimodifikasi untuk menyelesaikan model goal programming, seperti pada jurnal kasus keuangan oleh Halim, dkk (2015), memperoleh solusi optimal menggunakan metode lexicographic. Metode ini mengutamakan prioritas awal yaitu aset untuk mengoptimalkan laporan keuangan pada MayBank dengan enam tujuan yang berbeda. Selanjutnya, metode simpleks yang dimodifikasi juga pernah dibahas dengan yang kasus berbeda oleh Safitri, E dkk (2017) yang membandingkan metode simpleks modifikasi dan metode dual simpleks, serta menyimpulkan bahwa metode simpleks modifikasi menghasilkan jumlah iterasi yang lebih sedikit dari metode dual simpleks. Juga Safitri, E dkk (2019) menggunakan metode simpleks modifikasi untuk mengoptimalkan kadungan gizi makanan penderita Diabetes Mellitus.

Berdasarkan penelitian di atas, penelitian ini akan membahas kembali metode lexicographic goal programming dan simpleks yang dimodifikasi pada kasus PT. Pegadaian khususnya pada laporan keuangan. Penelitian ini bertujuan untuk mengetahui solusi optimal laporan keuangan PT. Pegadaian dan membandingkan metode lexicographic goal programming dan simpleks yang dimodifikasi dalam laporan keuangan keuangan PT. Pegadaian.

\section{METODE}

\subsection{Prosedur Penelitian}

Penelitian ini merupakan penelitian kuantitatif dengan data yang digunakan adalah data sekunder. Prosedur yang dilakukan dalam menyelesaikan penelitian ini adalah menyusun data dalam tabel, menyusun model goal programming, selanjutnya menyelesaikan model menggunakan metode simpleks dan metode lexicographic, kemudian menganalisis hasil optimasi yang diperoleh. Berikut ini merupakan langkah dalam menyelesaikan model penelitian. 


\section{Langkah Pertama}

Memodelkan data menjadi bentuk model goal programming.

$$
\min z=\sum_{i=1}^{n} P_{i}\left(D B_{i}+D A_{i}\right)
$$

dengan kendala:

$$
\begin{gathered}
\sum_{i=1}^{n} a_{i j} x_{j}+D B_{i}-D A_{i}=b_{i} \\
x_{j}, D B_{i}, D A_{i} \geq 0 \geq 1
\end{gathered}
$$

dengan,

$x_{j} \quad$ : variabel keputusan ke-j,

$D B_{i} \quad$ : deviasi tingkat pencapaian dibawah target,

$D A_{i} \quad$ : deviasi tingkat pencapaian diatas target,

$b_{i} \quad$ : tujuan atau target ke- $i$,

$a_{i j} \quad$ : koefisien fungsi kendala,

$P_{i} \quad$ : faktor prioritas.

\section{Langkah Kedua}

Setelah memodelkan data menjadi model goal prgramming selanjutnya metode penyelesaian digunakan untuk mendapatkan hasil penelitian.

\subsection{Metode Lexicographic Goal Programming}

Menurut Sadeli, M \& Lili (2002), metode Lexicographic Goal Programming memiliki langkah-langkah sebagai berikut.

a. Mempartisi $z$ menjadi beberapa $z_{i}, i=1,2, \ldots, m$ sesuai dengan setiap prioritas dengan deviasinya.

b. Menggunakan row $0($ goal $i, i=1,2, \ldots, m): z_{i}-P_{i} D A_{i}-P_{i} D B_{i}=0$

c. Mensubstitusikan row 0 ke tujuan ( $g o a l$ ) yang bersesuaian berdasarkan setiap deviasinya

d. Menyusun tabel awal simpleks goal programming menggunakan row 0 dan variabel-variabel deviasi bawah.

e. Memperhatikan prioritas pertama yang memiliki koefisien positif terbesar kemudian menjadi kolom pivot yang ditetapkan sebagai variabel masuk.

f. Menghitung baris pivot dengan ${ }^{2} / a_{i j}$ dengan rasio positif terkecil, sebagai variabel keluar.

g. Menetapkan elemen pivot.

h. Menyusun tabel simpleks goal programming baru, dengan menghitung nilai baris pivot baru.

i. Mencek kembali tujuan pertama, dikatakan optimal dan sudah tercapai apabila diperoleh $z_{1}=0$, jika kondisi tersebut tidak terpenuhi maka kembali ke langkah 5. Setelah goal 1 tercapai dan diminimalkan maka baru dapat dilanjutkan ke goal berikutnya dengan langkah yang sama.

j. Solusi dikatakan optimal apabila $z_{1}=z_{2}=\cdots=z_{n}=0$.

\subsection{Metode Simpleks yang Dimodifikasi}

Metode simpleks yang dimodifikasi mempunyai langkah-langkah sebagai berikut (Mulyono, 2007). 
a. Menyusun tabel awal simpleks berdasarkan variabel-variabel deviasi sebagai permulaan variabelvariabel solusi layak awal. Menghitung baris $Z_{j}-C_{j}$.

b. Menentukan kolom pivot sebagai variabel masuk berdasarkan nilai kolom $Z_{j}-C_{j}$ dengan nilai positif terbesar.

c. Menentukan baris pivot sebagai variabel keluar yaitu baris pivot dengan berpedoman pada $b_{i} / a_{i j}$ dengan rasio terkecil dimana $b_{i}$ adalah nilai sisi kanan dari setiap persamaan dan $a_{i j}$ adalah nilai kolom pemutarnya.

d. Menghitung nilai variabel keluar (baris pivot) dengan rumus

Nilai baris tabel baru variabel masuk $=\frac{\text { nilai variabel keluar (baris pivot)lama }}{\text { angka variabel masuk (kolom pivot) }}$

e. Menghitung nilai baris baru lainnya dengan menggunakan rumus

Baris baru $=$ baris lama $-($ koefisien variabel masuk $\times$ nilai variabel keluar tabel baru $)$

f. Menghitung baris $Z_{j}-C_{j}$ yang baru.

g. Memeriksa optimalitas, yaitu jika pada tingkat prioritas $Z_{j}-C_{j} \leq 0$ keseluruhan maka solusi telah tercapai.

\subsection{Desain Penelitian}

Data penelitian merupakan data sekunder yang diambil dari website resmi PT. Pegadaian yaitu: data aset, data liabilitas, data ekuitas, data pendapatan dan data beban. Data yang diambil adalah data lima tahun dari tahun 2014 sampai dengan 2018. Selanjutnya data-data tersebut digunakan sebagai alat bantu untuk membuat suatu model matematika dalam bentuk goal programming, kemudian akan diselesikan menggunakan metode lexicographic dan metode simpleks yang dimodifikasi.

\section{HASIL DAN PEMBAHASAN}

Berdasarkan penelitian Putri, Y.E dan Astuti Y.P (2017), di dalam laporan keuangan terdapat unsur yang menentukan posisi keuangan, yaitu: liabilitas, ekuitas dan juga unsur yang berkaitan dengan pengukuran kinerja dalam laporan laba rugi adalah penghasilan (pendapatan) dan beban. Oleh karena itu penelitian ini mengambil data di PT. Pegadaian berdasarkan unsur-unsur tersebut. Data yang digunakan dalam optimalisasi laporan keuangan PT. Pegadaian adalah data aset, data liabilitas, data ekuitas, data pendapatan dan data beban. Data diambil dari Laporan Tahunan PT. Pegadaian mulai tahun 2014 sampai tahun 2018 yang diperoleh dari internet web (http://www.pegadaian.co.id).

Tabel 1. Laporan Keuangan PT. Pegadaian 2014-2018 (dalam Rp)

\begin{tabular}{lcccccc}
\hline \multicolumn{1}{c}{ Goal } & $\mathbf{2 0 1 4}$ & $\mathbf{2 0 1 5}$ & $\mathbf{2 0 1 6}$ & $\mathbf{2 0 1 7}$ & $\mathbf{2 0 1 8}$ & Total \\
\hline Aset & 35.344 .988 & 40.169 .730 & 43.582 .354 & 48.687 .092 & 52.791 .188 & 220.575 .352 \\
Liabilitas & 24.136 .150 & 26.576 .373 & 28.329 .458 & 30.476 .832 & 32.674 .699 & 142.193 .512 \\
Ekuitas & 11.208 .837 & 13.593 .357 & 16.252 .895 & 18.210 .260 & 20.116 .489 & 79.381 .838 \\
Pendapatan & 7.800 .893 & 8.782 .877 & 9.807 .328 & 10.522 .796 & 11.464 .462 & 48.378 .356 \\
Beban & 5.556 .650 & 5.729 .554 & 6.342 .747 & 7.184 .828 & 7.829 .860 & 32.643 .639 \\
\hline
\end{tabular}




\subsection{Menentukan Variabel yang Akan Digunakan}

Variabel-variabel yang digunakan dalam penelitian ini adalah sebagai berikut.

$x_{i} \quad$ : Nilai laporan keuangan pada tahun ke $-i$

$D B_{i}$ : Deviasi negatif dari tujuan ke- $i$

$D A_{i}$ : Deviasi positif dari tujuan ke- $i$

$P_{i} \quad$ : Prioritas ke- $i$

$b_{i} \quad$ : Jumlah total setiap goal ke- $i$

$A_{i} \quad$ : Jumlah aset tiap ke- $i$

$L_{i} \quad$ : Jumlah liabilitas tiap ke- $i$

$E_{i} \quad$ : Jumlah ekuitas tiap ke- $i$

$N_{i} \quad$ : Jumlah pendapatan tiap ke- $i$

\subsection{Menentukan Fungsi Kendala}

Fungsi kendala yang ditentukan dalam penelitian ini adalah sebagai berikut.

1. Kendala sasaran memaksimalkan aset

$$
\sum_{i=1}^{5} A_{i} x_{i}+D B_{i}-D A_{i}=b_{i}
$$

2. Kendala sasaran meminimalkan liabilitas

3. Kendala sasaran memaksimalkan ekuitas

$$
\sum_{i=1}^{5} L_{i} x_{i}+D B_{i}-D A_{i}=b_{i}
$$

$$
\sum_{i=1}^{5} E_{i} x_{i}+D B_{i}-D A_{i}=b_{i}
$$

4. Kendala sasaran memaksimalkan pendapatan

$$
\sum_{i=1}^{5} P_{i} x_{i}+D B_{i}-D A_{i}=b_{i}
$$

5. Kendala sasaran meminimalkan beban

$$
\sum_{i=1}^{5} B_{i} x_{i}+D B_{i}-D A_{i}=b_{i}
$$

\subsection{Menentukan Fungsi Tujuan}

Fungsi tujuan dalam kajian ini ditentukan sebagai berikut.

$$
\min z=P_{1} D B_{1}+P_{2} D A_{2}+P_{3} D B_{3}+P_{4} D B_{4}+P_{5} D A_{5}
$$

Data optimalisasi laporan keuangan PT. Pegadaian pada Tabel 1, selanjutnya dapat dibentuk dalam rumusan model goal programing sebagai

dengan fungsi kendala

$$
\min z=P_{1} D B_{1}+P_{2} D A_{2}+P_{3} D B_{3}+P_{4} D B_{4}+P_{5} D A_{5}
$$




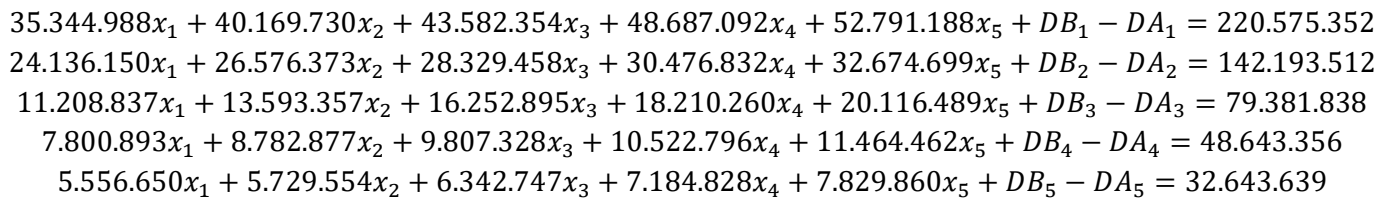

Model goal programming di atas, selanjutnya diselesaikan dengan menggunakan dua metode yang berbeda diantaranya metode lexicographic goal programming dan metode simpleks yang dimodifikasi.

Pertama, metode lexicographic goal programming.

Langkah 1 : Mempartisi fungsi tujuan menjadi beberapa tujuan $z_{i}, i=1,2, \ldots, m$ dengan

$$
z_{i}=\min \left(D B_{i}\right)
$$

Langkah 2 : Gunakan row 0 untuk setiap goal $I$, Row 0 (goal $i): z_{i}-D B_{i}=0$

Langkah 3 : Mensubstitusikan setiap row 0 dengan goal $i$ pada setiap kendala berdasarkan deviasi.

Langkah 4 : Menyusun tabel awal simpleks goal programming.

Langkah 5 : Menentukan kolom pivot dengan memperhatikan prioritas pertama.

Langkah 6 : Menentukan baris pivot.

Langkah 7 : Solusi dikatakan optimal jika seluruh $z_{1}=z_{2}=\cdots=z_{n}=0$.

Tabel 2. Tahap Awal untuk Lexicographic Goal Programming

\begin{tabular}{|c|c|c|c|c|c|c|c|c|c|c|}
\hline Item & $x_{1}$ & $x_{2}$ & $x_{3}$ & $x_{4}$ & $x_{5}$ & $D A_{1}$ & $D B_{1}$ & $\mathrm{DA}_{2}$ & $\mathrm{DB}_{2}$ & RHS \\
\hline $\begin{array}{l}\text { Row 0 } \\
\text { (goal1) }\end{array}$ & 35.344 .988 & 40.167 .730 & 43.582 .354 & 48.687 .092 & 52.791 .188 & -1 & 0 & 0 & 0 & $z_{1}=220.575 .352$ \\
\hline $\begin{array}{l}\text { Row 0 } \\
\text { (goal2) }\end{array}$ & 24.576 .373 & 26.576 .373 & 28.329 .458 & 30.476 .832 & 32.674 .699 & 0 & 0 & -2 & 1 & $z_{2}=142.193 .512$ \\
\hline $\begin{array}{l}\text { Row } 0 \\
\text { (goal3) }\end{array}$ & 11.208 .837 & 13.593 .357 & 16.252 .895 & 18.210 .260 & 20.116 .489 & 0 & 0 & 0 & 0 & $z_{3}=79.381 .838$ \\
\hline $\begin{array}{l}\text { Row } 0 \\
\text { (goal4) }\end{array}$ & 7.800 .893 & 8.782 .877 & 9.807 .328 & 10.522 .796 & 11.464 .462 & 0 & 0 & 0 & 0 & $z_{4}=48.378 .356$ \\
\hline $\begin{array}{l}\text { Row } 0 \\
\text { (goal5) }\end{array}$ & 5.556 .650 & 5.729 .554 & 6.342 .747 & 7.184 .828 & 7.829 .860 & 0 & 0 & 0 & 0 & $z_{5}=32.643 .639$ \\
\hline$D B_{1}$ & 35.344 .988 & 40.167 .730 & 43.582 .354 & 48.687 .092 & 52.791 .188 & -1 & 1 & 0 & 0 & 220.575 .352 \\
\hline$D B_{2}$ & 24.576 .373 & 26.576 .373 & 28.329 .458 & 30.476 .832 & 32.674 .699 & 0 & 0 & -1 & 1 & 142.193 .512 \\
\hline$D B_{3}$ & 11.208 .837 & 13.593 .357 & 16.252 .895 & 18.210 .260 & 20.116 .489 & 0 & 0 & 0 & 0 & 79.381 .838 \\
\hline$D B_{4}$ & 7.800 .893 & 8.782 .877 & 9.807 .328 & 10.522 .796 & 11.464 .462 & 0 & 0 & 0 & 0 & 48.378 .356 \\
\hline $\mathrm{DB}_{5}$ & 5.556 .650 & 5.729 .554 & 6.342 .747 & 7.184 .828 & 7.829 .860 & 0 & 0 & 0 & 0 & 32.643 .639 \\
\hline
\end{tabular}

Tabel 3. Iterasi 6 Metode Lexicographic Goal Programming (Solusi Optimal)

\begin{tabular}{|c|c|c|c|c|c|c|c|c|c|c|}
\hline item & $x_{1}$ & $x_{2}$ & $x_{3}$ & $x_{4}$ & $x_{5}$ & $D A_{1}$ & $D B_{1}$ & $D A_{2}$ & $D B_{2}$ & RHS \\
\hline Row 0 (goal1) & 0 & 0 & 0 & 0 & 0 & 0 & -1 & 0 & 0 & $z_{1}=0$ \\
\hline Row 0 (goal2) & 0 & 0 & 0 & 0 & 0 & 0 & 0 & -1 & 0 & $z_{2}=0$ \\
\hline Row 0 (goal3) & 0 & 0 & 0 & 0 & 0 & 0 & 0 & 0 & 0 & $z_{3}=0$ \\
\hline Row 0 (goal4) & 0 & 0 & 0 & 0 & 0 & 0 & 0 & 0 & 0 & $z_{4}=0$ \\
\hline Row 0 (goal5) & 0 & 0 & 0 & 0 & 0 & 0 & 0 & 0 & 0 & $z_{5}=0$ \\
\hline$D A_{3}$ & -261.795 & -139.947 & 0 & -252.977 & 0 & $-0,54$ & 0,54 & 0,26 & $-0,2$ & 3.186 .129 \\
\hline$D A_{4}$ & -9553.16 & $-33.689,2$ & 0 & -161.990 & 0 & $-0,01$ & 0,01 & $-0,32$ & 0,32 & 957.800 \\
\hline$x_{5}$ & 0,3634 & 0,6682 & 0 & 1,06 & 1 & $\begin{array}{c}-6,4 \\
x 10^{-7}\end{array}$ & $\begin{array}{c}6,4 \\
x 10^{-7}\end{array}$ & $\begin{array}{c}3,5 \\
x 10^{-7}\end{array}$ & $\begin{array}{c}-3,5 \\
x 10^{-7}\end{array}$ & 0,72 \\
\hline$x_{3}$ & 25559,7 & $-750,8$ & 1 & $-3884,6$ & 0 & $\begin{array}{c}-4,5 \\
x 10^{-7}\end{array}$ & $\begin{array}{c}4,5 \\
x 10^{-7}\end{array}$ & 0,0083 & $-0,083$ & 4,186 \\
\hline$D B_{5}$ & -283.665 & -486.734 & 0 & -183.901 & 0 & $-0,203$ & 0,203 & 0,106 & $-0,10$ & 436.141 \\
\hline
\end{tabular}


Kedua, metode simpleks yang dimodifikasi.

Langkah 1 : Menyusun tabel awal menggunakan variabel-variabel deviasi sebagai permulaan variabel-variabel solusi dasar yang layak. Hitung baris $Z_{j}-C_{j}$

Langkah 2 : Menentukan variabel masuk yaitu kolom pivot (masukkan variabel non-basis)

Langkah 3 : Menentukan variabel keluar yaitu baris pivot dengan berpedoman pada $b_{i} / a_{i j}$ dengan rasio positif terkecil.

Langkah 4 : Menentukan elemen pivot.

Langkah 5 : Membentuk tabel simpleks baru.

Langkah 6 : Menghitung baris $Z_{j}-C_{j}$ yang baru.

Langkah 7 : Memeriksa optimalitas, yaitu jika pada tingkat prioritas $Z_{j}-C_{j} \leq 0$ keseluruhan maka solusi telah tercapai.

Tabel 4. Awal Simpleks yang Dimodifikasi

\begin{tabular}{|c|c|c|c|c|c|c|c|c|c|c|c|c|c|c|}
\hline & & & 0 & 0 & 0 & 0 & 0 & 0 & 1 & 1 & 0 & 0 & \multirow[t]{2}{*}{ RHS } & \multirow[t]{2}{*}{ rasio } \\
\hline$P_{k}$ & $C_{i}$ & $V B$ & $x_{1}$ & $x_{2}$ & $x_{3}$ & $x_{4}$ & $x_{5}$ & $D A_{1}$ & $D B_{1}$ & $D A_{2}$ & $D B_{2}$ & $D A_{3}$ & & \\
\hline$P_{1}$ & 1 & $D B_{1}$ & 35.344 .988 & 40.169 .730 & 43.582 .354 & 48.687 .092 & 52.791 .188 & -1 & 1 & 0 & 0 & 0 & 20.575 .352 & 4,17 \\
\hline$P_{2}$ & 1 & $D B_{2}$ & 24.576 .373 & 26.576 .373 & 28.329 .458 & 30.476 .832 & 32.674 .699 & 0 & 0 & -1 & 1 & 0 & 142.193 .512 & 4,35 \\
\hline$P_{3}$ & 1 & $D B_{3}$ & 11.208 .837 & 13.593 .357 & 16.252 .895 & 18.210 .260 & 20.116 .489 & 0 & 0 & 0 & 0 & -1 & 79.381 .838 & 3,94 \\
\hline$P_{4}$ & 1 & $D B_{4}$ & 7.800 .893 & 8.782 .877 & 9.807 .328 & 10.522 .796 & 11.464 .462 & 0 & 0 & 0 & 0 & 0 & 48.378 .356 & 4,21 \\
\hline \multirow[t]{2}{*}{$P_{5}$} & 1 & $D B_{5}$ & 5.556 .650 & 5.729 .554 & 6.342 .747 & 7.184 .828 & 7.829 .860 & 0 & 0 & 0 & 0 & 0 & 32.643 .639 & 4,16 \\
\hline & & $P_{1}$ & 35.344 .988 & 40.169 .730 & 43.582 .354 & 48.687 .092 & 52.791 .188 & -1 & 0 & -1 & 0 & 0 & & \\
\hline \multirow{4}{*}{\multicolumn{2}{|c|}{$Z_{j}-C_{j}$}} & $P_{2}$ & 24.576 .373 & 26.576 .373 & 28.329 .458 & 30.476 .832 & 32.674 .699 & 0 & -1 & -2 & 1 & 0 & & \\
\hline & & $P_{3}$ & 11.208 .837 & 13.593 .357 & 16.252 .895 & 18.210 .260 & 20.116 .489 & 0 & -1 & -1 & 0 & -1 & & \\
\hline & & $P_{4}$ & 7.800 .893 & 8.782 .877 & 9.807 .328 & 10.522 .796 & 11.464 .462 & 0 & -1 & -1 & 0 & 0 & & \\
\hline & & $P_{5}$ & 5.556 .650 & 5.729 .554 & 6.342 .747 & 7.184 .828 & 7.829 .860 & 0 & -1 & -1 & 0 & 0 & & \\
\hline
\end{tabular}

Tabel 5. Iterasi 6 Metode Simpleks yang Dimodifikasi (Solusi Optimal)

\begin{tabular}{|c|c|c|c|c|c|c|c|c|c|c|c|c|c|c|}
\hline & & & 0 & 0 & 0 & 0 & 0 & 0 & 1 & 1 & 0 & 0 & 1 & RHS \\
\hline$P_{k}$ & $C_{i}$ & $V B$ & $x_{1}$ & $x_{2}$ & $x_{3}$ & $x_{4}$ & $x_{5}$ & $D A_{1}$ & $D B_{1}$ & $D A_{2}$ & $D B_{2}$ & $D A_{3}$ & $D B_{3}$ & \\
\hline$P_{1}$ & 1 & $D A_{3}$ & -261.795 & -139.947 & 0 & -252.977 & 0 & $-0,54$ & 0,54 & 0,26 & $-0,2$ & -1 & 1 & 3.186 .129 \\
\hline$P_{2}$ & 1 & $D A_{4}$ & -9553.16 & $-33.689,2$ & 0 & -161.990 & 0 & $-0,01$ & 0,01 & $-0,32$ & $-0,32$ & 0 & 0 & 957.800 \\
\hline$P_{3}$ & 0 & $x_{5}$ & 0,3634 & 0,6682 & 0 & 1,06 & 1 & $\begin{array}{c}-6,4 \\
x 10^{-7}\end{array}$ & $\begin{array}{c}6,4 \\
x 10^{-7}\end{array}$ & $\begin{array}{c}3,5 \\
x 10^{-7}\end{array}$ & $\begin{array}{c}-3,5 \\
x 10^{-7}\end{array}$ & 0 & 0 & 0,72 \\
\hline$P_{4}$ & 0 & $x_{3}$ & 25559,7 & $-750,8$ & 1 & $-3884,6$ & 0 & $\begin{array}{c}-4,5 \\
x 10^{-7}\end{array}$ & $\begin{array}{c}4,5 \\
x 10^{-7}\end{array}$ & 0,0083 & $-0,083$ & 0 & 0 & 4,186 \\
\hline \multirow[t]{3}{*}{$P_{5}$} & 1 & $D B_{5}$ & -283.665 & -486.734 & 0 & -183.901 & 0 & $-0,203$ & 0,203 & 0,106 & $-0,10$ & 0 & 0 & 436.141 \\
\hline & & $P_{1}$ & -261.795 & -139.947 & 0 & -252.977 & 0 & $-0,54$ & $-0,46$ & $-0,74$ & $-0,2$ & -1 & 0 & \\
\hline & & $P_{2}$ & -9553.16 & $-33.689,2$ & 0 & -161.990 & 0 & $-0,01$ & $-0,86$ & $-1,32$ & $-0,32$ & 0 & -1 & \\
\hline \multirow{3}{*}{\multicolumn{2}{|c|}{$Z_{j}-C_{j}$}} & $P_{3}$ & 0 & 0 & 0 & 0 & 0 & 0 & -1 & -1 & 0 & 0 & -1 & \\
\hline & & $P_{4}$ & 0 & 0 & 0 & 0 & 0 & 0 & -1 & -1 & 0 & 0 & -1 & \\
\hline & & $P_{5}$ & -283.665 & -486.734 & 0 & -183.901 & 0 & $-0,203$ & $-0,797$ & $-0,894$ & $-0,10$ & 0 & -1 & \\
\hline
\end{tabular}

Optimalisasi laporan keuangan PT. Pegadaian pada penelitian ini menggunakan variabel deviasi untuk menilai keoptimalan setiap sasaran, sehingga diperoleh hasil pada Tabel 6.

Tabel 6. Hasil Variabel Devasional

\begin{tabular}{lcc}
\hline \multicolumn{1}{c}{ Sasaran } & Variabel deviasi negatif $D B_{i}$ & Variabel deviasi positif $D A_{i}$ \\
\hline Memaksimalkan aset & 0 & 0 \\
Meminimalkan liabilitas & 0 & 0 \\
Memaksimalkan ekuitas & 0 & 3.186 .129 \\
Memaksimalkan pendapatan & 0 & 957.800 \\
Meminimalkan beban & 436.161 & 0 \\
\hline
\end{tabular}


Berdasarkan Tabel 6 didapatkan bahwa untuk sasaran pertama memaksimalkan aset dengan deviasi negatif $\left(D B_{1}\right)$ adalah 0 maka tujuan tercapai dan deviasi positif $\left(D A_{1}\right)$ adalah 0 , artinya tidak ada perubahan total aset sebesar Rp. 220.575.352 untuk 5 tahun. Untuk sasaran kedua meminimalkan liabilitas dengan deviasi positif $\left(D A_{2}\right)$ adalah 0 maka tujuan tercapai dan deviasi negatif $\left(D B_{2}\right)$ adalah 0, artinya tidak ada perubahan total liabilitas sebesar Rp. 142.193 .512 untuk 5 tahun. Untuk sasaran ketiga memaksimalkan ekuitas dengan deviasi negatif $\left(D B_{3}\right)$ adalah 0 sedangkan deviasi positif $\left(D A_{3}\right)$ adalah Rp. 3.186.129. Hal ini menunjukkan bahwa kekayaan ekuitas tercapai dan total ekuitas dapat ditingkatkan sebesar Rp. 3.186.129 per tahun. Untuk sasaran keempat memaksimalkan pendapatan dengan deviasi negatif $\left(D B_{4}\right)$ adalah 0 sedangkan deviasi positif $\left(D A_{4}\right)$ adalah Rp. 957.800. Hal ini menunjukkan bahwa pendapatan tercapai dan total pendapatan dapat ditingkatkan sebesar Rp. 957.800 per tahun. Untuk sasaran kelima meminimalkan beban dengan deviasi positif $\left(D A_{5}\right)$ adalah 0 sedangkan deviasi negatif $\left(D B_{5}\right)$ adalah Rp. 436.141. Hal ini menunjukkan bahwa jumlah beban dapat diturunkan Rp. 436.141 per tahun.

Sehingga dapat disimpulkan bahwa prioritas pertama sampai prioritas kelima dari tujuan dapat terpenuhi, ini menjelaskan bahwa PT. Pegadaian memiliki kinerja laporan keuangan yang baik. Namun, ditemukan tiga tujuan yang dapat diubah untuk memperbaiki kinerja laporan keuangan yaitu total ekuitas, total pendapatan dan total beban, sehingga dapat meningkatkatkan hasil kinerja laporan tersebut. Adapun total ekuitas dapat ditingkatkan sebesar Rp. 3.186.129 per tahun, total pendapatan dapat ditingkatkan sebesar Rp. 957.800 dan total beban dapat diturunkan sebesar Rp. 436.141 per tahun.

\section{SIMPULAN}

Hasil optimalisasi laporan keuangan PT. Pegadaian menggunakan metode lexicographic goal programming dan simpleks yang dimodifikasi berdasarkan hasil analisa dan tujuan yang telah ditetapkan, diperoleh sebagai berikut.

1. Prioritas pertama sampai prioritas kelima dari tujuan dapat tercapai, artinya PT. Pegadaian memiliki kinerja laporan keuangan yang baik. Terdapat 3 tujuan yang dapat diperbaiki untuk meningkatkan kinerja laporan tersebut. Total ekuitas dapat ditingkatkan sebesar Rp. 3.186.129 per tahun, total pendapatan dapat ditingkatkan sebesar Rp. 957.800 dan total beban dapat diturunkan sebesar Rp. 436.141 per tahun.

2. Penyelesaian model goal programming dengan metode lexicographic goal programming dan simpleks yang dimodifikasi mendapatkan nilai solusi optimal dan jumlah iterasi yang sama.

\section{DAFTAR PUSTAKA}

Babaei, H. dkk. (2009). Lexicographic Goal Programming Approach for Portfolio Optimization. Journal of Industrial Engineering International, June 2009, Vol. 5, No. 9, 63-75.

Halim, B.A, dkk. (2015). Bank Financial Statement Management using a Goal Programming Model. Procedia-Social and Behavioral Sciences, 211(2015), 498504.

Mulyono, S. (2007). Riset Operasi Edisi Revisi 2007. Jakarta: LPFUI. Jakarta. 
Orumie, U. C dan D. W. U. Ebong. (2013). An Efficient Method of Solving Lexicographic Linear Goal Programming Problem. International Journal of Scientific and Research Publications, October 2013, Vol. 3, Issue 10, 1-8.

Putri, Y.E dan Puji, Y.A. (2017). Analisis Keoptimalan Laporan Keuangan Menggunakan Goal Programming (Studi Kasus Data Bank BTN). Jurnal Ilmiah Matematika, Vol. 3, No. 6, 134-141.

Sadeli, M \& Lili. (2002). Dasar-dasar Akuntansi Edisi 1. Jakarta: Bumi Aksara.

Safitri, E. dkk. (2017). Penyelesaian Program Gol Menggunakan Metode Simpleks Modifikasi dan Metode Dual Simpleks. Jurnal Sains Matematika dan Statistika, 3(1), 10-19.

Safitri, E. dkk. (2019). Optimalisasi Kandungan Gizi Makanan pada Penderita Diabetes Mellitus menggunakan Metode Simpleks Modifikasi (Studi Kasus: Rumah Sakit Ibnu Sina Pekanbaru). Jurnal Sains Matematika dan Statistika, 5(2), 72-80. 